Special Issue of Gender and Education: 'Taking Stock', forthcoming 2015

\title{
The problem of gender categorisation: Addressing dilemmas past and present in gender and education research
}

\author{
Prof Becky Francis (King's College London) \& Prof Carrie \\ Paechter (Goldsmiths, University of London)
}

Contact:

Becky Francis

Department of Education and Professional Studies

King's College London

e-mail: Becky.Francis@kcl.ac.uk 
The problem of gender categorisation: Addressing dilemmas past and present in gender and education research

\begin{abstract}
Developments in the field of gender theory as applied to education since the 1970s are briefly reviewed in order to highlight key challenges and debates around gender categorisation and identification in gender and education. We argue that conundrums of categorisation have haunted, and continue to haunt, the field of gender theory, and empirical applications (such as the case of education) in particular. We explain how we have attempted to address some of the conundrums arising in our own theoretical work, and analyse remaining challenges that we feel the field of education needs to address in order to advance theoretically. Identifying two key tensions underpinning this empirical dilemma of gender categorisation - the tension between agency and determinism in gender identification, and that between gender deconstruction and gender analysis - we seek to weave a path through some of these complex debates, and to indicate ways in which they may be addressed in future work. We argue that in order to avoid essentialism and reification of gender distinction, we need to apply a 'threefold' analysis that incorporates three different elements in our categorisation of gender: spectator perspective; respondent perspective; and social context.
\end{abstract}




\section{The problem of gender categorisation: Addressing dilemmas past and present in gender and education research}

\section{Introduction}

To take stock of theoretical developments in gender and education is to traverse a host of issues: not only the evolution of gender theory as applied to education, educational institutions and their participants; but also conceptions of childhood, youth, the professions, educational contexts, different social identities and their inter-relation, and so on. Nevertheless, these are the complexities this article seeks to chart, in its response to the call to appraise theoretical developments in the field of gender and education studies. In what follows, our focus is on gender theory as it has developed in Anglophone nations since the 1970s, when research in gender and education first began to form a critical mass (Skelton \& Francis, 2007). Specifically, we are going to discuss gender theory as it has been applied to children and young people.

\section{The development of gender theory as applied in education}

The analysis of gender and gender inequality, precipitated by feminist concerns about social inequalities on the basis of designation as 'male' or 'female', has always been troubled by categorisation. Second wave feminists initially referred to sex differences (categorising subjects as male or female in application of a dominant, dualistic lens). However, the problematic of this categorisation, with its underpinning assumptions that all subjects have bodies identifiable as either male or female, and that 'natural' differences in behaviour emanate from these bodies, was quickly identified (see e.g. Kessler \& McKenna, 1978). This approach was therefore supplanted by the creation and application of the concept of gender (Stoller, 1968; Oakley, 1970). This theoretical construct appeared to escape the essentialism of 'sex', capturing the way in which different patterns of behaviour (and indeed bodies) are socially constructed, rather than innate. This distinction was both radical and influential: the concept of gender challenged the idea that body was destiny, and hence was of central import to feminist thinking. It also made a vital contribution for trans people, as it provided a way of describing their existence, in some ways making their lives legible (Paechter, 2003a).

However, as we have variously outlined elsewhere in greater detail, problems with the concept of gender have subsequently emerged, due to dualistic premises which reflect an integral, if hidden, attachment to the concept of sex (Francis, 2002; 2008; Paechter, 2003). These include an increasing tendency for 'gender' to be used as a straightforward substitute for 'sex' in everyday speech, with the result that the initial benefits of the distinction have gradually been eroded.

Meanwhile, theoretical explanations for the transmission and perpetuation of gender differences and inequalities were becoming more sophisticated. The concept of patriarchy was undermined by two different bodies of work: one that highlighted how women could also oppress one another (and even oppress men) on the basis of factors such as 'race', class, sexuality, age and so on (hooks, 1982; Hill-Collins, 1991); and the other that challenged concepts of power as a possession of some groups at the expense of others, and instead showed power to be dispersed. Indeed, the work of Foucault $(1977,1978,1980)$, which had a profound impact on gender theory in the late 1980s, 
critiqued assumptions that power is a possession, as well as highlighting the necessary accompaniment of resistance. Social reproduction theory, which in the 1970s facilitated many key analyses of the role of education institutions and classroom practices in the reproduction of gender inequalities, began also to be critiqued for its inability to explain resistance, or to account for the nuanced diversity of gender productions (Anyon, 1983; Riddell, 1989). These various developments generated increased attention to fluidity and contradictions in gender construction, the intersection of gender identities with those of 'race', social class and others, and interest in the complexities of contested power relations within, as well as between groups. Despite this, as we discuss later in the paper, even such intersectional analyses acknowledging diversity on different structural axes have largely been applied to groups in the global metropolitan North, ignoring the often different needs of people in less economically-privileged national contexts.

In terms of conceptions of gender, and our theme of categorisation, it was within this context that the applications 'masculine' and 'feminine' (dualistic expressions of gender) began to be seen as limited, and inadequate to capture the diversity manifesting within these categories. To reflect this, the categories began to be employed in plural, as 'masculinities' and 'femininities'. RW Connell's work made a significant intervention here, analysing how a hierarchy of masculinities can operate in different contexts (1995). Connell also showed how, albeit all men/boys benefit from patriarchy, dominant 'hegemonic' masculinities may subjugate others.

However, these more plural analyses by no means escape the dualism at the heart of the concept 'gender'. Indeed, these theories of 'multiple masculinities and femininities' have been accused of further reifying dualistic gender distinctions, and revealing the continuing (essentialist) tie back to the sexed body underpinning these apparently socially constructed gender productions. This can be seen in the ways in which all behaviours expressed by boys/men are categorised as reflecting a kind of masculinity (whether hegemonic or otherwise), and all those produced by girls are read as expressing varieties of femininity. Indeed, the 'multiple masculinities and femininities' approach has frequently manifested in typologies of masculinity and femininity, in gender and education research and elsewhere, a trend which Connell has lamented (Connell \& Messerschmidt, 2005). This approach, in which all expressions by men/boys are seen as forms of masculinity, is especially notable in Connell's concept of 'subordinate masculinities' (Connell, 1995). However apparently 'feminine' their behaviour, boys not part of locally hegemonic groups are still analysed as performing a type of (subordinate) masculinity, rather than performing femininity. As McInnes (1998) and Hood-William (1998) have identified, if behaviours produced by men/boys can only be read as masculine (and likewise for women/girls with regard to femininity), the categoriser is actually the body (sex), rather than gender. This application of sex as the invisible categoriser of masculinities and femininities illustrates what Hawkesworth (1997) has critiqued as the 'base/superstructure' model, where 'gender' is seen to flow directly from the sexed body: a position that can be seen as reverting to essentialism (as McInnes [1998] observes, in this case we might as well just apply 'sex'. See also Paechter, 2003). Yet this problematic conflation of 'sex' and 'gender' underpins much empirical work adopting 'gender' as a concept (Hawkesworth, 1997; Francis, 2002, 2008). 
Indeed, this invocation of the body ('sex') as the ghostly categoriser of gender has, for the most part, continued to be reflected in empirical analyses of gender and education (even that maintaining poststructuralist and other post-humanist influences). As one of us has argued elsewhere, this arguably has dangerous consequences: because female non-gender-traditional expression is not read as 'doing masculinity', or male nontraditional constructions as 'doing femininity', it tends to be gender-traditional behaviour that is identified and analysed by researchers of gender (Francis, 2002; 2008). This risks over-representation and reification of gender difference, and hence exacerbation of the gender dichotomy rather than contribution to its deconstruction.

Nevertheless, this conflation of sex/gender has been challenged in some quarters. Poststructuralist theorists returned to the deconstruction of the sex dualism initiated by early pioneers such as Garfinkel (1969) and Kessler \& Mckenna (1978). Judith Butler (1990) applied her poststructuralist lens in showing how both sex and gender are socially constructed: brought into being via binary gender discourses that inscribe bodies according to a (mythical) duality. This position therefore also 'queers' the heterosexist assumptions underpinning dualistic notions of the sex/gender binary. This understanding of sex as socially constructed to the same extent as is gender echoes the earlier and more body-focused work of Fausto-Sterling (1987, 1989,1993), who examined the discourses of biology and embryology to establish that these contain particularly gendered constructions of how human bodies develop and function. These constructions have embedded within them earlier dualisms in which female bodies, and how they develop, are understood as passive; male bodies and their developmental pathways as active. Butler's understanding of sex/gender as performative refuses essentialist ties to a sexed body. Hugely influential, this work was nevertheless primarily theoretical rather than empirical. Consequently, while generating numerous fruitful studies of the performance of gender (including in the education context), this did little to disrupt the continuing analysis of diverse performances of gender as reflecting either femininities for girls/women, or masculinities for boys/men. It was for this reason that the contribution of Jack Halberstam (1998) was stimulating. Halberstam drew on Butler's theoretical work to analyse production of masculinity as cut loose from men, in relation to the case of Drag Kings. This analysis of female masculinity prises apart the 'base/superstructure' connection between sex and gender, and challenges perceptions of gender as characterising the domains of exclusively sexed physical bodies (Francis, 2008b).

However, the identification of gender via performance, rather than bodies, is not without its problems (Francis, 2008b, 2010; Paechter, 2006). For as Becky has observed, this means analyzing expressions of gender, categorized according to rudimentary and highly stereotypical binaries (wherein attributes such as care, emotion, diligence, passivity etc are constructed as denoting femininity; and those such as strength, reason, confidence, action etc are seen to denote masculinity) (Francis, 2008). Indeed, this danger is clear in Halberstam's analysis of female masculinity: Carrie has characterized Halberstam's valorisation of masculinity as reflecting a sort of Boys' Own 1950s stereotype of middle-class masculinity (Paechter, 2006).

Moreover, in addition to the issue of categorization/ascription, the production of gender as a matter of choice has also been critiqued for a potential lack of acknowledgement of the role of the spectator - and of society more broadly - in gender intelligibility; and 
(relatedly) for a lack of acknowledgement of the way in which power is unequally distributed according to the ascription of Self or Other.

Hence, gender theory has clearly evolved in the period since gender and education began to emerge as a field in the 1970s, addressing a range of conceptual disputes, often

illuminated by challenges in empirical application. Nevertheless, issues of categorization, and related theoretical dilemmas of agency/determinism, and accounts of power, persist. Analyses of contexts, performances, and inequalities in the field of gender and education have continued to draw on a range of wider theory: while some researchers have maintained an interest in poststructuralism as expressed in the accounts of Foucault, Butler and others, others have returned to structuralism (especially the work of Bourdieu), or explored the potential of psycho-social perspectives. Others still have found fruitful the broader post-humanist work exemplified by Deleuze, Guattari and contemporaries for better attending the multifaceted material and cultural assemblages that establish gender and other aspects of identity (and their affects) in complex and unpredictable ways. Nevertheless, many of these approaches are applied to address issues other than the classification and construction of gender ${ }^{\mathrm{i}}$, and it is arguable that despite this rich array of theory, the field remains haunted by the underlying issue of categorization.

This haunting is further complicated by our awareness that many of the issues we are discussing are very much those of more privileged areas of the globe, in which many basic problems, such as equal access to education between boys and girls, have been overcome. We recognise that some of the theoretical questions we discuss pale into insignificance when we consider, for example, the gender-based violence pervading some schooling systems in places distant from the metropolitan global North (Bhana, $2005 \mathrm{a}, \mathrm{b}$ ). We also need to appreciate that not only are there good reasons to maintain gender distinctions based on sexed bodies, where these relate to access to important goods such as education and healthcare, but that many non-Western cultures recognise a greater range of gender expressions and identities than is the case in the regions that dominate these debates (Imperato-McGinley, 1979; Nanda, 1999).

\section{Our own attempts to address these challenges}

For both of us this previous body of work on gender theory has led to a series of questions and dilemmas concerning the relationships between bodies, gender attribution, gender identity claims and the nature of masculinity and femininity. For both of us, much of our work over the last ten years or so stems from an attempt to refine some of the theoretical concepts and propose ways through the maze, while maintaining a focus on how these play out with specific reference to children and schools. While we have approached these issues in different ways and to some extent with different conclusions, we share an unease with three elements of much contemporary gender theory, which relate to issues of gender categorization and power. First, we are concerned about the lack of transparent analysis of the ways gender attributions are constructed and applied in research and practice. In particular, we have both been concerned to explore what it means to make a claim, and for that claim to be legitimised, to a particular gender. Secondly, we are uneasy with the persistent reification of particular productions of masculinity and femininity, especially 
those associated with dominant males. These two issues are often closely inter-related. Thirdly, mainstream gender theory tends to be only partially rooted in embodiment, and, where embodiment is theorized and discussed, the focus has tended to be exclusively on adult bodies. There is work that pays careful attention to children's bodies - mainly but not exclusively carried out by researchers in gender and education ${ }^{\text {ii }}$. However, this has been overlooked by the most influential writers on gender theory, who have, with the exception of Connell, had little to say about education (Connell, 2010). While our attention in this article is largely to the first two points, we return to the issue of gender embodiment in children towards the end of the article.

Reflecting on the first issue, of gender identification and attribution. Halberstam's (1998) attention to gender attribution, and what it means to be recognised as a particular gender, reflects the earlier contribution of Kessler and McKenna (1978) and in particular their experiments regarding how adults make gender attribution judgements. They note that once an initial attribution is made, all subsequent judgments of an individual's gender are made in the light of this initial attribution. This insight supports Halberstam's emphasis on the response of spectators in gender attribution, reflecting also Butler's $(1990,1993,2004)$ focus on performance. Nevertheless, Carrie (Paechter, 2006a) has argued that this focus on gender attribution leaves little or no space for an individual's understanding of their own identity, for their ability to define their own gender by answering the question 'am I a man or a woman or something else entirely?' (Whittle, 2000: 7): 7. She suggests that while gender can indeed be seen as performative, the question of to whom this performance is aimed needs to be understood in as broad a way as possible, so that the performance of the gendered self not just to others, but to oneself, and the consequent self-recognition is seen as a central part of the claiming and consequent attribution of gender. While others do clearly have a role to play in establishing gender attribution, it is also important to recognise that if individuals are to have 'liveable lives' (Butler, 2004:8) they must be enabled to determine their gender and have it recognised, for example, through the use of appropriate pronouns. In this sense, gender attribution, and the legitimation of people in their preferred gender, are matters of respect as much as anything else.

In making these arguments, Carrie foregrounds notions of power and in particular considers these in relation to legitimacy and agency in gender ascription. While, she argues, legitimation is at least partly in the eye of the spectator, this raises problems for practical reasons to do with the configuration of actual bodies, coupled with Kessler and McKenna's (1978) gender schema, which suggests that, in the West at least, we attribute as male in the absence of significant clues to the contrary. In particular, she is concerned to preserve the liveability of those lives which do not fit hegemonic gendered forms of embodiment (Butler, 2004). She notes, for example, that the taking of testosterone for a relatively short period gives an antomically female body key signifiers of maleness, such as facial hair, a deeper voice and even male pattern baldness: such changes cannot so easily be made to anatomically male bodies. This means that if gender attribution is purely a matter for the observer, it will be enacted in a differential way between, for example, transmen and transwomen, with the former more likely to have their gender claims legitimated and accepted than the latter. In practice, this may indeed be the case. While the idea that gender is mutually constructed between individual and observer does partially deal with this problem, there still remains some level of discrimination with regard to legitimation and legitimacy. Carrie is concerned to develop theoretical 
principles that can facilitate individual agency and provide the discursive possibilities that improve intelligibility and livability (Butler 2004).

In this sense, Carrie's concerns and theoretical reflections on gender categorization and identification address philosophical questions of agency and what ought to be. This is distinct from Becky's primary preoccupation with issues of conceptual clarity, and for conceptual accounts that most accurately reflect the gendered social world. In her own explorations of gender construction and attribution, Becky has applied Bahktin's understandings of language to analyse the power of the monoglossic account of gender. Bahktin (1980) conceives monoglossic accounts as positing a totalising worldview which centralise particular socio-political readings and cultural expressions, in an attempt to purify and eradicate alternatives, and to achieve complete hegemony for the monoglossic account. Becky (Francis, 2010; 2012) applies the concepts of monoglossia and heteroglossia to gender, arguing that gendered behaviours, and the construct of gender itself, can be conceived as reflecting both monoglossia and heteroglossia. What is important about the monoglossic account of gender is its signifying power in spite of evident heteroglossia. Gender monoglossia appears to be able to present itself holistically, masking contradiction and dissonance even where these are evident. In her empirical work, for example, Becky notes how high achieving, popular high school students' performances of gender were shot through with heteroglossic contradiction, and indeed with aspects of performance usually ascribed to the opposite 'sex'; but that these students appeared to draw on particularly significant tropes of gendered performance to promote an overall impression of monoglossic gender stability, and mask/distract from inconsistency. These tropes were, for girls, an overt interest in stereotypically feminine pursuits such as fashion, celebrity, aesthetics, and heterosexuality (including the expression of 'precocious feminininty'); and for boys, heterosexuality and ability at sport (see Francis et al 2010).

The danger is that this monoglossic masking of gender heteroglossia is not identified by research, and that instead monoglossic, dualistic performances of masculinity and femininity are simply recorded (and thus re-inscribed) by research. Becky has worked to show the heteroglossic diversity at work in all performances of gender, asserting the import of these empirical analyses for deconstructing the mythic (monoglossic) binary account of sex/gender (Francis, 2010; 2012). Thus in relation to our second point concerning reification of particular productions of masculinity and femininity, Becky's work seeks to highlight both the ways in which subjects articulate and perpetuate gender monoglossia (and the power differentials produced by and producing the monoglossic account), while simultaneously highlighting the prevalent heteroglossic diversity that potentially disrupts and deconstructs gender monoglossia.

This approach also gives us a way to address the afore-mentioned question of legitimacy and gender attribution. Beyond being attuned to the fundamental role of the spectator in shaping constructions of gender, we also need to attend to the multifarious gender discourses that underpin the individual gender performance and its reading. Application of Bahktin's work insists on the mutual construction of gender viability - if spectators reject a gender production as illegitimate this reading inevitably impacts on the producers' authenticity and subjectivity (Francis, 2012). Hence the power of the 
'reader' to assign gender is, for Becky, an integral aspect of 'authentic' identification (Kessler and McKenna, 1978).

Like Becky, Carrie has also been concerned to unpick what is understood and implied by discourses of masculinity and femininity, and to uncover how power relations operate in this regard. For example, she has been concerned to analyse and clarify Connell's (Connell, 1987, 1995, 2002; Connell and Messerschmidt, 2005) work on hegemonic masculinity and, to some extent, 'rescue' it from several decades of misinterpretation. She has focused on reasserting the localised nature of hegemonic masculinity and pointing out that many of the problems associated with the concept arise from a reification of particular forms of masculinity as hegemonic. In particular, she has argued that, while stereotypical masculinities remain dominant in many circumstances, this is not always the case, and, indeed, they may be subordinate in some contexts. Both Carrie and Becky have also been at pains to disentangle the relationship between productions of masculinity, femininity, other facets of identity, and power. Carrie has explored the construction of hegemonic and other productions of masculinity, critiquing Connell's view that all non-hegemonic masculinities are necessarily subordinate (Paechter, 2012) and Becky has questioned the extent to which these productions are actually 'masculine' (Francis, 2002, 2008). We argue that a range of productions of masculinity and femininity can be present in any particular context (indeed, we both maintain this to be the case within individual subjectivities, Francis, 2010, 2012; Paechter 2007), and that these are connected by complex and mobile relationships of power and resistance. Carrie has also worked on the relationship of 'hegemonic masculinities' to productions of femininity, arguing, following Connell (1987, 1995, 2002 ), that neither girls performing the locally hegemonic masculinity nor girls performing a locally emphasised femininity can be seen as hegemonic. This is because hegemonic masculinity is fundamentally defined as the form which, in that local context, justifies male dominance. Girls embodying and performing these forms of masculinity are not hegemonic in this sense, but transgressive (see Paechter, 2007, for discussion).

This shared concern for philosophical and conceptual precision with regard to issues of gender attribution stems from our mutual aspiration to optimize out conceptual tools via which to effectively challenge gender inequality, and ultimately to further the project of deconstructing gender binaries.

\section{Unresolved questions}

So, in reflecting on the evolutions, circulations and lines of flight in gender theory as developed and applied in the education field, it is clear not only that have we come far, but also that much remains to be done. Despite the myriad issues and philosophical conundrums briefly signalled above, it tends to be the case that we continue to attribute gender as if it were the same as (dualistic) sex, and to analyse performance in relation to (binarised) constructions of masculinity and femininity. This status quo is perhaps not surprising given the particular empirical context of gender and education research: education institutions, wherein dualistic productions of gender remain determinedly and overtly inscribed. We work in classrooms where registers are organized into lists of 'the girls' and 'the boys'; where boys and girls are frequently made to sit alternately, to line up separately, and/or to compete, in production of school disciplinary practices; 
where lavatories are segregated, uniforms are gender distinct, and girls and boys are separated for certain subjects (or even for schooling). Attempts to disrupt or 'do differently' in these contexts can seem facile. Nevertheless, our complicity in these practices in naming and analyzing according to gender [sex] further interpolates and reinscribes the binary and associated monoglossic practices.

These problems are exacerbated by the tendency in gender and education research to identify gendered patterns that reflect the status quo, rather than analyzing elements of performance that trouble monoglossic productions of gender (Francis, 2010). The difficulty, here and above, is that power is unevenly mobilised according to gender, and that patterns of behaviour, social discourse, and discrimination, do manifest in continuing gender inequality. As many authors have pointed out, gender remains the pivotal unit of analysis in feminist work. If we do not identify and analyse research participants according to gender, the feminist project is rendered inoperable.

This brings us back to the issue of categorization of gender, which has provoked much commentary from us both, and which constitutes a central conundrum we wish to highlight in this article. During the half-century since early pioneers such as Stoller (1968) and Kessler \& McKenna (1978) rejected the determinist binary model of sex, the social construction of the sex dualism (Fausto-Sterling, 1987; Butler, 1990) has become increasingly socially evident. Indeed, in recent years the greater accessibility of hormone treatments and surgery, alongside the growing visibility of groups such as Intersex ${ }^{\mathrm{iii}}$ (facilitated by the internet and social media), has meant that the fallacy of the sex dualism is increasingly difficult to uphold. This is not in any way to suggest that subjects that do not 'fit' the monoglossic, binary construction of gender/sex are no longer problematised and/or impossibilised. However, the more they are represented, the harder it is to deny their existence.

Yet, as we have seen, the deconstruction of the gender binary comprises not only a challenge to the monoglossic gender order, but also to feminist theory. We arrive at two fundamental tensions, which are necessary to confront in order assess productive ways forward. The first is between agency and/or determinism in legitimation of gender: gender as a point of claimed (agentic) identification against the more deterministic recognition that gender identification has to be recognized and legitimated in order to 'pass' as 'authentic', and is produced by a collage of different discursive and material elements within a specific context. The second tension is whether we should aim to deconstruct gender entirely, or not. The answer to this second question precipitates further practical dilemmas concerning the recognition, in the present, that gender identity involves inequalities of power and outcome which need to be captured and documented. As Connell (2010) points out, this is particularly important for those in the global South, for whom, for example, struggles against gendered violence (Bhana, $2005 a, b)$ require, at least at present, the retention of normative gender categories, in order to be able to support and implement policies for practical action. If we are serious about fighting entrenched sexism wherever it is found, we need to be able to recognise it, and this requires us to be able to recognise and record differences in the treatment of men and women, boys and girls. Similarly, if we are unable to recognise a relationship as being same-sex, it becomes impossible to campaign for such relationships to be universally recognised. At the same time, the very act of categorization required for 
such documentation reproduces precisely those gender binaries which we may, perhaps, wish to deconstruct.

These dilemmas evidently cannot be resolved within a single article. Nevertheless, we offer here some analysis to stimulate further discussion on these highly significant conceptual challenges. Both tensions are of course inter-related. The first tension, between gender as a point of claimed identification, and gender as something that has to be recognized and legitimated, speaks both to theories of identification, the validity or otherwise of gender claims, and to practical and ethical matters of categorization during research. As we have argued above, as a socially constructed category, gender is necessarily mutually constructed, and gender identification/recognition relies both on the subject and spectators, and the multi-facted bricolage of material (including embodied) and discursive elements present and implicated in the construction of the interaction. The latter bricolage, 'network' or 'assemblage' is increasingly being taken seriously via application of Bakhtian, Actor Network Theory, Communities of Practice (Paechter, 2003a,2003d, 2006c, 2007) and/or Deleuzian lenses. Indeed, referring to the latter perspective, Fox and Alldred (2013) maintain that it

"...establishes a fundamental difference of focus between anthropocentric and antihumanist ontologies: between exploring the social interactions of active, sensemaking human agents and mapping impersonal affective flows and territorialisations within assemblages." (p. 774)

All four theoretical lenses enable this important philosophical move in dissolving the binary between individual-agency and society-context-determinism, in addition to addressing the limitations of a purely discursive analysis by accounting for the impact of materiality/embodiment on constructions (see Francis, 2012). We personally find Bakhtinian analyses (Becky) and approaches involving communities of practice (Carrie) as more convincing and empirically productive accounts for analytical application in social research ${ }^{\text {iv. }}$. However, in terms of our role as researchers, the question remains as to a) how we are categorizing gender in our fieldwork and analyses; and b) the implications of this, in simultaneously interpolating and perpetuating gender even as we critique its effects. With regard to the former, we have already discussed the dilemma of categorizing gender by the body/by a self-claim/by performance (gendered attributes), and this clearly remains an area for further conceptual debate and empirical trial. With regard to the latter, this question returns us to the well-rehearsed, circular predicament which some have attempted to circumnavigate via the adoption of a 'strategic essentialist' approach (DePalma, 2009: 6). This approach recognizes the temporary necessity of identity labels, in order to identify power inequalities, and to potentially challenge and deconstruct them. However, it still falls prey to the critique that the continued focus on gender identity categories and 'differences' reifies and perpetuates the gender binary.

With regard to the second tension: whether we should aim to deconstruct gender entirely, or not, we can only speculate at present. Any attempt at resolution, and committed work towards this end, would require a significant leap of the imagination in order to gain any understanding of what it might be like to live in a genderless future. We two feel slightly differently about this as a utopia, but have found the issue fruitful to debate together. At present, investments in gender (binary or otherwise) are so strongly 
visceral that to move away from the idea that everyone has some form of gender identity (including identities such as Intersex, Gender queer and/or Androgynous) is difficult to imagine. Many newly recognized gender identities (notably trans) have been hard fought for, and often invest in gender distinction rather than gender deconstruction. As Butler (and Williams, 2014) argues:

Sometimes there are ways to minimize the importance of gender in life, or to confuse gender categories so that they no longer have descriptive power. But other times gender can be very important to us, and some people really love the gender that they have claimed for themselves. If gender is eradicated, so too is an important domain of pleasure for many people. And others have a strong sense of self bound up with their genders, so to get rid of gender would be to shatter their self-hood. I think we have to accept a wide variety of positions on gender. Some want to be gender-free, but others want to be free really to be a gender that is crucial to who they are.

Even those who see themselves as non-binary may not necessarily prefer to live in a world in which gender had become a meaningless concept (albeit there are many of us that $d o$ see this deconstruction of gender as a utopian prospect). In considering these issues, therefore, it behoves us to be mindful that our response to the increasing visibility and political power of currently marginalised individuals and groups does not lead to a denial of identifications for which they have fought long and hard. We also need, as suggested above, to ensure that a deconstruction of gender led by the metropolitan global North does not inadvertently make it harder to identify and unpick power relations based around normative gender forms in the wider global arena (Connell, 2010).

Because gender binaries are currently so strongly embedded in our psychic identifications, whether these are along, across, or straddling binary lines, it is currently almost unthinkable for most of us that we could de-invest in these identities and move to a gender-free world. However, it is possible that over generations of gradual diversification (the intensification of heteroglossia; changes in power relations within communities of gendered practice) such investments might be displaced. Indeed, the speed of changes in the legal and social recognition of minoritised gender and sexual identities in some parts of the world - unthinkable just a generation ago- might point to feasibility here. What is unclear, however, is what this might mean for individuals and their identifications. It might be argued that, rather than trying to eliminate gender, we should instead aim for the end of discrimination between gendered identities/positionings, with a strongly heteroglossic understanding of the range of possibilities these might encompass. However, this approach risks overlooking the way that social practices mobilise distinctions to perpetuate hierarchies and inequalities of power (often but not always tied to essentialised constructs such as 'race' or sex), which continue to marginalize and oppress particular groups. At the same time, history shows us how identifications, points of recognition and the reified objects that accompany these (including bodies and how they are understood) change in social and personal importance alongside other historical changes. So even though the aim of immediate elimination of gender is potentially ethically fraught as well as practically implausible, that does not necessarily imply that it is not a viable aim for the longer-term future. 
This brings us to the question of 'what we do now', and productive ways that enable us to move between the present place of needing our (workable and accurate) gender categories, to the point at which gender becomes deconstructed. Analysis of gender monoglossia and gender heteroglossia facilitates attention to continuing power inequalities and analyzable discursive and material practices which work to reproduce and naturalise gender, but simultaneously enables attention to the heteroglossic contradiction and turbulence which is increasingly troubling gender monoglossia. (For full discussion of this theoretical application, see Francis 2012; and for empirical application, see Francis 2010). And in order to effect this analysis, without falling into some of the problematics of categorization identified above, we suggest that we need to mobilise analyses and modes of categorization that simultaneously reflect three different lenses. These are:

1) the spectator view. In other words, the perception of researchers as observers in the field, of parents, other students/peers, and of institutions, that our respondents are (for example), girls, boys, women, men, other, or uncategorisable.

2) the individual respondents' view. This means actualizing within our research tools the facility for respondents to categorise themselves as they wish (e.g. providing respondents with the option of female/male/other -twith the option to specify what that other is - as is now common in Germanyv).

3) the features of the local discursive and material collage which enables the gender production and recognition. In other words, describing and analyzing the ways in which gender production is informed by bodies, aesthetic adornment/decoration, gendered expressions of behaviour/attributes, material objects and cultural discourses within the local context, and so on, all of which enable, constrain, construct, and deconstruct intelligible productions of gender.

All of this needs to be openly declared and evidenced so that other researchers may contest and deconstruct the resulting analyses; but the very act of making this complex analysis transparent functions to problematise, rather than to reify and naturalise, both the gender binary and the concept of gender.

If we did take this approach, combining three different lenses of categorization, how would it affect children - so frequently the subjects of our research? Children are in an interesting position in that in some ways it is harder for them to use their bodies to make gender identity claims, but in other ways it is easier. It is harder because they are not subject, in the ways that adults are, to Kessler and McKenna's (1978) gender schema: most of the ways in which maleness becomes an automatic attribution in the absence of other clues are not available to them because of their lack of physical maturity. This means that, in situations of gender-neutral dress, hairstyle, etc., we may have to pay closer attention to the detail of children's gender identity claims and performances in order to give due respect and legitimation to individuals' understandings of who they are. This adds further complexity to the spectator view element of our gender categorization, if only because spectators themselves, mindful of these ambiguities, tend to be more provisional in their initial attributions when it comes to children, particularly girls, for whom (through the tomboy label) self-presentation in ways stereotypically associated with boys is a socially acceptable and not uncommon phenomenon. On the other hand, children struggling against potential attributions which go against their felt identities can, at least while clothed, make convincing 
performances more easily than many others. Their performances are not undermined, as those of adults may be, by breasts, deep voices, Adam's apples, male pattern baldness or beard growth. This allows some children to experiment and play with gender in ways that are not always available to others - though again this experimentation is more available to girls, through the adoption of tomboy identities and self-presentations, than it is to boys. Conversely, we know from the research literature that sometimes gender binaries can be exacerbated for children, with gender category maintenance work (Davies, 1989) causing especially inflexible boundaries and policing. This is particularly the case for very young children, for whom concepts of gender constancy are not well understood. Adult constructions, such as 'the Metrosexual', and so on, which embrace heteroglossia, are also less available to children, leaving boys in particular with fewer non-conformist options. Finally, in regard to the local collage which shapes gender production, it may be important to be attuned to the relative lack of agency for children in this regard (for example given their mandatory attendance at school, and their exclusion from certain sites and activities on the basis of age).

\section{Concluding remarks}

In summary, we have reviewed developments in the field of gender and education, charting conceptual developments and continuing conundrums, and highlighting the problem of classification as a key dilemma continuing to 'haunt' gender and education. Identifying two key tensions underpinning this empirical dilemma - the tension between agency and determinism in gender identification, and that between gender deconstruction and gender analysis - we have sought to weave a path through some of the multifarious and complex debates relating to these. Articulating some of the ways we have approached these theoretical challenges in our recent work, we returned to the issue of gender categorisation in relation to empirical analyses in education. We argued that in order to avoid essentialism and the reification of gender distinction, we need to apply three different elements in our categorisation and analysis of gender: spectator perspective; respondent perspective; and social context. This is not without its challenges, and may require new methodological techniques to actualise. Nevertheless, we posit that this 'three-fold' approach to gender categorisation will better enable us to simultaneously 'hold' the elements contributing to (heteroglossic and mercurial) gender productions, without compromising their complexity. This in turn supports the justification of our continued analysis of gender, and its (for the moment) resilient role in patterning inequalities of power.

\section{References}

Anyon, J. (1983) Intersections of gender and class: accommodation and resistance by working class and affluent females to contradictory sex role, in: S. Walker \& L. Barton (eds) Gender, Class and Education (Lewes: Falmer).

Atkinson, E. and DePalma, R. (2009) 'Unbelieving the matrix: Queering consensual heteronormativity', Gender and Education, 21(1): 17-29.

BBC (2013) "Germany allows 'indeterminate' gender at birth", http://www.bbc.co.uk/news/world-europe-24767225

Bhana, D. (2005a). "Show me the panties": girls play games in the school ground. In C. Mitchell \& J. Reid-Walsh (Eds.), Seven Going on Seventeen (pp. 163-172). New York: Peter Lang. 
Bhana, D. (2005b). What matters to boys and girls in a black primary school in South Africa. Early Child Development and Care, 175(2), 99-111.

Blaise, M. (2005). Playing it Straight: uncovering gender discourses in the early childhood classroom. London: Routledge.

Butler, J. (1990). Gender Trouble: feminism and the subversion of identity. London: Routledge.

Butler, J. (1993). Bodies that Matter: on the discursive limits of 'sex'. London: Routledge.

Butler, J. (2004). Undoing Gender. New York: Routledge.

Butler, J., \& Williams, C. (2014). Judith Butler addresses TERFs and the work of Sheila Jeffreys and Janice Raymond. Retrieved from http://theterfs.com/2014/05/01/judith-butler-addresses-terfs-and-the-work-ofsheila-jeffreys-and-janice-raymond/

Connell, R. W. (1987). Gender and Power. Cambridge: Polity Press.

Connell, R. W. (1995). Masculinities. Cambridge: Polity Press.

Connell, R. W. (2002). Gender. Cambridge: Polity Press.

Connell, R. W. (2010). Kartini's children: on the need for thinking gender and education together on a world scale. Gender and Education, 22(6), 603-615.

Connell, R. W., \& Messerschmidt, J. W. (2005). Hegemonic masculinity: rethinking the concept. Gender and Society, 19(6), 829-859.

Davies, B. (2003). Shards of Glass (Second ed.). Cresshill, New Jersey: Hampton Press.

Evans, J., Rich, E., Davies, B., \& Allwood, R. (2008). Education, Disordered Eating and Obesity Discourse: fat fabrications. London: Routledge.

Fausto-Sterling, A. (1987). Society writes biology/biology constructs gender. Daedalus, 116, 61-76.

Fausto-Sterling, A. (1989). Life in the XY corral. Women's Studies International Forum, 12(3), 319-331.

Fausto-Sterling, A. (1993). The five sexes: why male and female are not enough. The Sciences, March/April, 20-24.

Foucault, M. (1977). Discipline and Punish (A. Sheridan, Trans.). London: Penguin.

Foucault, M. (1978). The History of Sexuality Volume One (R. Hurley, Trans.). London: Penguin.

Foucault, M. (1980). Power/Knowledge: selected interviews and other writings 19721977. Hemel Hempstead, Herts: Harvester Press.

Francis, B. (2012) Gender monoglossia, gender heteroglossia: the potential of Bakhtin's work for re-conceptualising gender, Journal of Gender Studies, 21 (1) 1-15.

Francis, B. (2010) Re/theorising Gender: Female masculinity and male femininity in the classroom?, Gender and Education, 22 (6) 477-490.

Francis, B., Skelton, C. \& Read, B. (2010) The simultaneous production of educational achievement and popularity: how do some pupils accomplish it? British Educational Research Journal, 36 (2) 317-340.

Francis, B. (2008) Engendering Debate: how to formulate a political analysis of the divide between genetic bodies and discursive gender, Journal of Gender Studies, 17 (3) 211-223.

Francis, B. (2008b) 'Teaching Manfully? Exploring gendered subjectivities and power via analysis of men teachers' gender performance, Gender and Education, 20 (2) 109-122. 
Francis, B. (2002) Relativism, Realism, and Reader-Response Criticism: An analysis of some theoretical tensions in research on gender identity' (2002) Journal of Gender Studies, 11 (1) 39-54.

Gallas, K. (1998). "Sometimes I Can Be Anything": power, gender and identity in a primary classroom. New York: Teachers' College Press.

Gard, M. (2001). Dancing around the 'problem' of boys and dance. Discourse, 22(2), 213225.

Gordon, T., \& Lahelma, E. (1996). School is like an ants' nest: spatiality and embodiment in schools. Gender and Education, 8(3), 301-310.

Halberstam, J. (1998). Female Masculinity. Durham: Duke University Press.

Hill-Collins, P. (1991) Black Feminist Thought (New York: Routledge).

hooks, b. (1982) Ain't I a Woman: Black women and feminism (London: Pluto Press).

Imperato-McGinley, J., Peterson, R. E., Gautier, T., \& Sturia, E. (1979). Androgens and the evolution of male gender-identity among male pseudohermaphrodites with 5alpha reductase deficiency. New England Journal of Medicine, 300, 1233-1237.

Kehily, M. (2001). Bodies in School: young men, embodiment and heterosexual masculinities. Men and Masculinities, 4(2), 173-185.

Kelly, D. M., Pomerantz, S., \& Currie, D. (2005). Skater girlhood and emphasised femininity: 'you can't land an ollie properly in heels'. Gender and Education, 17(3), 229-248.

Kessler, S., \& McKenna, W. (1978). Gender: an Ethnomethodological Approach. New York: John Wiley and Sons. .

Martin, B. (2011). Children at Play. Stoke-on-Trent: Trentham Books.

Nanda, S. (1999). The Hijras of India. London: Wadsworth.

Nespor, J. (1997). Tangled up in School. Mahwah, New Jersey: Lawrence Erlbaum Associates.

Paechter, C. (2003a). Masculinities and femininities as communities of practice. Women's Studies International Forum, 26(1), 69-77.

Paechter, C. (2003b). Masculinities, femininities and physical education: bodily practices as reified markers of community membership. In C. Vincent (Ed.), Social Justice, Education and Identity (pp. 137-152). London: RoutledgeFalmer.

Paechter, C. (2003c). Power, bodies and identity: how different forms of physical education construct varying masculinities and femininities in secondary schools. Sex Education, 3(1), 47-59.

Paechter, C. (2003d, September 2003). Reconceptualising the gendered body: learning and constructing masculinities and femininities in school. Paper presented at the British Educational Research Association Annual Conference, Heriot-Watt University, Edinburgh, UK.

Paechter, C. (2006a). Masculine femininities/feminine masculinities; power, identities and gender. Gender and Education, 18(3), 253-263.

Paechter, C. (2006b). Reconceptualising the gendered body: learning and constructing masculinities and femininities in school. Gender and Education, 18(2).

Paechter, C. (2007). Being Boys, Being Girls: learning masculinities and femininities. Maidenhead, Berks: Open University Press.

Paechter, C. (2010). Tomboys and girly-girls: embodied femininities in primary schools. Discourse, 31(2), 221-235.

Paechter, C. (2012). Bodies, identities and performances: reconfiguring the language of gender and schooling'. Gender and Education, 24(2), 229-241. 
Paechter, C., \& Clark, S. (2007). Who are tomboys, and how do we recognise them? Women's Studies International Forum(30), 342-354.

Prendergast, S. (2000). 'To become dizzy in our turning': girls, body-maps and gender as childhood ends. In A. Prout (Ed.), The Body, Childhood and Society (pp. 101-124). Basingstoke, Hants: Macmillan.

Renold, E. (2005). Girls, Boys and Junior Sexualities: exploring children's gender and sexual relations in the primary school. London: Routledge.

Rich, E., \& Evans, J. (2009). Now I am NObody, see me for who I am: the paradox of performativity. Gender and Education, 21(1), 1-16.

Stoller, R. J. (1968). Sex and Gender: on the development of masculinity and femininity. New York: Science House.

Whittle, S. (2000). The Transgender Debate: the crisis surrounding gender identities. Reading: South Street Press.

\footnotetext{
i There are exceptions, including the notable attempt by Fox and Alldred (2013) to apply Deleuzian theory to the construction of sexuality (relevant to, and by implication applicable to, the related construction of gender).

ii See, for example, Davies, 2003; Evans, Rich, Davies, \& Allwood, 2008; Gallas, 1998; Gard, 2001; Gordon \& Lahelma, 1996; Imperato-McGinley et al., 1979; Kehily, 2001; Kelly, Pomerantz, \& Currie, 2005; Nanda, 1999; Prendergast, 2000; Blaise, 2005; Clark, 2010; Martin, 2011; Nespor, 1997; Paechter, 2003b, 2003c, 2003d, 2006b, 2007; Renold, 2005; Rich \& Evans, 2009)

iii We recognise that those people with 'intersex' bodies include a range of identifications, sometimes including binarised gender identities, while others actively identity as Intersex.

iv The lack of empiricism in Deleuzian accounts often limits analysis of assemblages/machines to speculation; bereft of methods to assess which elements of an assemblage have enabled or constrained outcomes (or indeed what these multifarious 'molecular' elements might be).

v See BBC, 2013, reporting that Germany has creted a new category of 'indeterminate' (or leaving gender category items blank) on children's birth certificates to cater for Intersex. This in turn has proved contentious; see for example coverage by OLL Australia, https://oii.org.au/23183/germany-third-genderbirth-certificates/
} 